Clinical Medicine

Poster

Abstract ID: 141

\title{
Methodology and reliability of corneo-pterygium total area measurements utilizing image analysis method
}

\author{
Mohd Radzi Hilmi ${ }^{\mathrm{a}}$ | Khairidzan Mohd Kamal ${ }^{\mathrm{b}}$ | Mohd Zulfaezal Che Azemin ${ }^{\mathrm{a}}$ | Azrin Esmady Ariffin ${ }^{\mathrm{c}}$ \\ ${ }^{a}$ Department of Optometry and Vision Sciences, Kulliyyah of Allied Health Sciences, International \\ Islamic University Malaysia
}

${ }^{b}$ Department of Ophthalmology, Kulliyyah of Medicine, International Islamic University Malaysia

${ }^{c}$ Faculty of Optometry and Vision Science, SEGi University, Malaysia

Introduction: To propose an objective method of quantifying pterygium total area utilizing image analysis method. Methods: 68 primary pterygium participants were selected from patients who visited an ophthalmology clinic. We adopted image analysis software in calculating the size of invading pterygium to the cornea. The marking of calculated area was done manually and the total area size was measured in pixel. The calculated area is defined as the area from the apex of pterygium to the limbal-corneal border. Then, from pixel it was transformed into a percentage (\%), which represents the corneo-pterygium total area relative to the total corneal surface area. Intra-observer reliability testing was performed by the tracing process was repeated twice with a different sequence of images at least one (1) month apart. Inter-observer reliability were also examined by having two observers. Intraclass correlation (ICC) and scatter plot were used to describe the reliability of measurement. Results: The overall mean $(N=68)$ of corneo-pterygium total area was $44.36 \pm 12.31 \%(\mathrm{Cl}: 41.38-47.34)$. Reliability for ROI demarcation of corneo-pterygium total area were excellent with intra and interagreement of $0.999(95 \% \mathrm{Cl}, \quad 0.998-0.999 ; P<0.001)$ and $0.998(95 \% \mathrm{Cl}, \quad 0.997-$ 0.999; $P<0.001)$ respectively. Conclusions: The image analysis method is useful, reliable and practical in a clinical setting to objectively quantify corneo-pterygium total area regardless of the size and shapes. By having a standardized measurement of corneopterygium total area, the actual effects of the pterygium progression on changes of corneal curvature can be investigated.

KEYWORDS: Pterygium, corneo-pterygium, total area, image analysis 